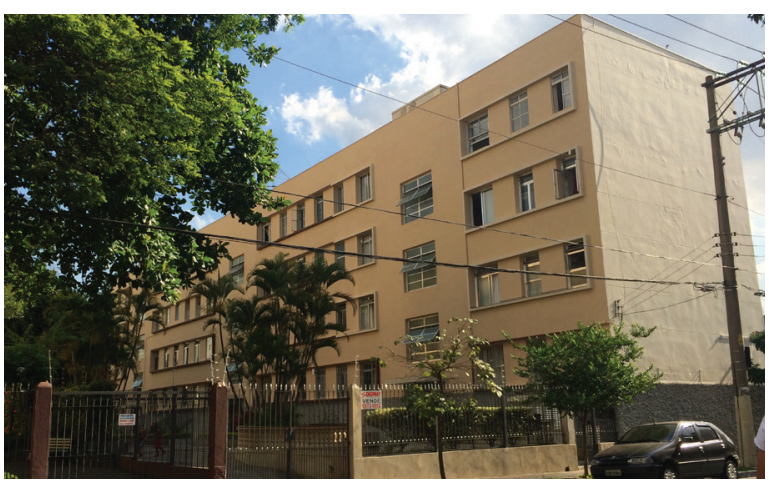

*Professora na graduação e pós-graduação da Faculdade de Arquitetura e Urbanismo da Universidade de São Paulo (FAU-USP), autora dos livros Entre a estética e o hábito: o Departamento de Habitação Popular, Rio de Janeiro (1946-1960) e Blocos de Memórias: habitação social, arquitetura moderna e patrimônio cultural e coautora de Domesticidade, gênero e cultura material. Coordena o Grupo de Pesquisa Patrimônio cultural, história e crítica.

\title{
Habitar o presente, construir o passado: história oral e patrimônio nos conjuntos residenciais modernos em São Paulo
}

Inhabiting the present, building the past:" oral history and heritage in São Paulo"s Modern housing complexes

Flávia Brito do Nascimento*

\section{Resumo}

O presente artigo tem por objetivo discutir - patrimônio cultural e o lugar da memória nos conjuntos residenciais construídos pelos Institutos e Aposentadorias e Pensões (IAPs) na cidade de São Paulo nas décadas de 1940 e 1950. A partir do projeto de história oral com seus residentes, discutimos a elaboração do passado e seus sentidos para o presente face aos processos de transformação arquitetônica e urbana na metrópole. Em que medida, sob o olhar dos sujeitos sociais os conjuntos são referências culturais? Como pensar a sua perpetuação às gerações futuras diante das demandas constitucionais de ampliação do que pode ser considerado patrimônio cultural? O olhar dos moradores, a partir de suas vivências cotidianas no passado e no presente, revela profundos atrelamentos (seja na apropriação, seja na crítica) aos programas históricos de habitação no Brasil promovidos pelos IAPs. A partir da história oral, pretendeu-se discutir as trajetórias de vida nos conjuntos e suas relações com a preservação na contemporaneidade.

Palavras-chave: História oral, Habitação social, Institutos de aposentadoria e Pensões
Abstract

This paper aims to discuss cultural heritage and the place of memory in the housing complexes built by the Retirement and Pension Institutes (IAPs, for its acronym in Portuguese) in the City of São Paulo in the 1940s and 50s. Based on an oral history project featuring residents of these complexes, we discuss the construction of the past and its meanings in light of the architectural and urban transformations in the city. To what extent are the housing complexes considered cultural references by these social actors? How would we go about perpetuating these buildings for future generations, in light of the constitutional requirements for expanding what is considered as cultural heritage? The residents' accounts of both their past and present experiences reveal deep connections to (whether in their appropriation or criticism of) the historical housing programs promoted by the IAPs in Brazil. This oral history will contribute to discussing accounts of life in the housing complexes and their relationship with modernday preservation practices.

Keywords: Oral history, Social housing Retirement and Pension Institutes 


\section{Introdução}

Inserindo-se no debate sobre a expansão da

1. Este trabalho contou a assistência de pesquisa dos alunos da graduação da Faculdade de Arquitetura e Urbanismo da Universidade de São Paulo (FAUUSP) Pedro Felix e Danilo Ferreira, bolsistas do Programa Unificado de Bolsas da Universidade de São Paulo entre agosto de 2015 e agosto de 2016, aos quais agradeço. agenda de pesquisas sobre a habitação social e do patrimônio cultural no Brasil, este artigo tem por objetivo apresentar trabalho de pesquisa de história oral feito com moradores de conjuntos residenciais construídos entre os anos 1940 e 1950 pelos Institutos de Aposentadorias e Pensões em São Paulo e região metropolitana ${ }^{1}$. De maneira inédita foram realizadas entrevistas com moradores e moradoras dos conjuntos residenciais focando as histórias de vida, as formas de morar e de trabalho, a história urbana e os sentidos do patrimônio cultural.

cais que pode construir novos sólidos laços que possibilitem que os conjuntos residenciais permaneçam às gerações futuras. Nesta perspectiva, parece importante compreender os conjuntos habitacionais como parte dos processos históricos e urbanos e, como tais, soluções plausíveis à moradia e à qualidade de vida. A salvaguarda dos conjuntos tem se mostrado um grande desafio para os gestores, implicando na compreensão mais alargada das relações históricas do morar, da capacidade do Estado fiscalizar e gerir e na necessidade de ações dialógicas com os moradores na busca por construções coletivas de significados para o patrimônio.

Com a Constituição Federal de 1989 os preceitos de patrimônio cultural brasileiro foram legalmente transformados, incluindo expressões que extrapolam o excepcional e incluem toda sorte de temas da cultura. É no encontro dos necessários e aprofundados saberes técnicos (de fora do âmbito local) com as experiências e valorações lo-
É significativo problematizar a preservação da habitação de interesse social no Brasil e na América Latina mobilizando bibliografia recente sobre as identidades e alteridades no patrimônio cultural contemporâneo, na sua vertente crítica (HARRISON, 2013). A partir das experiências de memó- 
ria e de cotidiano, trabalhar no sentido da superação da perspectiva colonizadora dos discursos preservacionistas. Para tanto, é preciso constituir criticamente e em conjunto com a sociedade civil argumentos, ações, debates e disputas sobre a preservação do patrimônio.

Smith (1995) chamou de "authorized heritage discourse" - discurso autorizado do patrimônio - as práticas que são conformadas a partir dos anos 1960 grosso modo para o patrimônio europeu, sobretudo por ação da Unesco. Partindo de práticas e saberes técnicos que se auto-referenciam e tem a habilidade de falar sobre o patrimônio (donde o discurso autorizado), faz-se a seleção do que pode ser considerado patrimônio. Este discurso de autoridade sobre o patrimônio constitui e legitima o que é o patrimônio e determina quem tem a habilidade de falar sobre ele e sobre seus significados. Objetivamente, ele acaba por determinar quem pode falar sobre o patrimônio. O discurso autorizado do patrimônio será o estruturador das práticas patrimoniais após os anos 1960, focando a atenção em objetos esteticamente agradáveis que as gerações atuais devem cuidar e proteger e passar às gerações futuras. Com isso, forja sensos de identidade baseados mormente no passado. Neste processo, há um acento grande na materialidade como portadora de sentidos que são naturalizados e tratados como imanentes. Ulpiano Meneses (2009) chama também a atenção para a naturalização das valorações do patrimônio cultural no Brasil, com engajamentos de maneira frequentemente passiva às materialidades e numa tendência à exclusão de discursos contraditórios ou contestativos. Mas, patrimônio imaterial no Brasil constituiu deste os anos 2000 outras bases conceituais que, em diversos aspectos, ajudaram a colocar os sujeitos no centro de valoração nas políticas do patrimônio. Ao girar em torno do conceito de "referência cultural", os sujeitos e suas significâncias podem conferir sentidos às práticas sociais e, também, às preexistências. Ainda segundo o historiador, isso tem colocado um desafio ainda maior para a superação da falsa dicotomia material/imaterial, restando o patrimônio edificado encapsulado em discursos estéticos. Repovoar o patrimônio é uma ação necessária. (MENESES, 2017)

Os debates para a patrimonialização do legado habitacional moderno estimulam uma reflexão sobre o tensionamento do "discurso autorizado do patrimônio". (SMITH, 2006) Na medida que em muitos dos conjuntos são desconsiderados nos seus valores estético-estilísticos - os quais são comumente a base das valorações patrimoniais - a sua permanência e as ações de salvaguarda fomentam as possibilidades de alargamento do campo patrimonial e a consideração para além dos crivos interpretativos autorizados. No caso brasileiro sabe-se que as amarras intelectuais dos arquitetos modernos com as políticas de patrimônio e o entrelaçamento entre historiografia da arquitetura e as práticas seletivas implicou e 
vem implicando em dificuldades de preservação de edifícios de habitação social. (NASCIMENTO, 2016) No caso da habitação social, mesmo a legitimidade historiográfica dada pela expansão da agenda de pesquisas e o reconhecimento da produção habitacional moderna feita por autores como Cavalcanti (1987), Bonduki (1998), Antunes (1997), Aravecchia-Botas (2016) e Bruna (2010) e notadamente pelo Grupo de Pesquisas Pioneiros da Habitação Social, não tem sido suficiente para sistematizar ações de preservação.

Questiona-se o quanto foi possível extrapolar as relações com a legitimidade historiográfica nas práticas de patrimonialização recente. Em que medida tem-se conseguido, efetivamente, superar as preservações da arquitetura moderna para além da escrita da história e de modo mais permeável às práticas e representações dos sujeitos sociais nas suas valorações e significados?

Investigações como os de Graciela de Garay para o México, Rosa Aboy para a Argentina, Michel e Derainne para a França, ao trabalharem com a história oral junto aos moradores, mostraram o quanto os sujeitos sociais se relacionam com o projeto habitacional que o constituiu. Passados tantos anos da ocupação e da dissolução do programa de moradia estatal, restam os objetos os materiais e suas lembranças. Dialogar sobre a vida nos conjuntos, com os aportes metodológicos da história oral, ajuda a problematizar e dimensionar o impacto dos projetos modernos na vida dos trabalhadores e o significado dos modelos de vivenda na vida cotidiana e dos processos históricos vividos pelos moradores nos conjuntos habitacionais. E, mesmo tempo, refletir sobre os interesses e condições de sua preservação na cidade contemporânea, como parte da história do trabalho e dos trabalhadores no Brasil.

\section{Sobre conjuntos residenciais e preservação: o lugar dos sujeitos sociais}

Inúmeros conjuntos residenciais foram construídos em todo Brasil a partir do fornecimento público de habitação entre o final dos anos 1930 até o início dos anos 1960. O Estado geriu e organizou a moradia para o trabalhador até a década de 1960, quando o projeto político de fornecimento de moradias foi superado pelo BNH - Banco Nacional de Habitação, que teve outros crivos ideológicos e formais. $\mathrm{O}$ universo dos conjuntos residenciais construídos no Brasil entre 1930 e 1964 é amplo, não tendo havido homogeneidade na produção. Esta foi vasta, com variações tipológicas, tecnológicas, urbanísticas e de filiação teórica: há edifícios em altura em meio ao tecido urbano consolidado, tais como o Japurá (de Eduardo Kneese de Melo) e o Anchieta (dos Irmãos Roberto) em São Paulo, grandes conjuntos de edificações laminares em meio a áreas verdes combinados com casas isoladas como o Realengo e Vila Guiomar (de Carlos Frederico Ferreira), soluções espetaculares de exceção como o Pedregulho e grandes produções massivas como 
os conjuntos do IAPI de Bangu, Moça Bonita e Penha, no Rio de Janeiro. Todas são importantes e de grande impacto urbano, não importando se de arquitetos de renome ou produzidas nas repartições dos institutos. (KOURY, 2019)

A investigação dos problemas de preservação dos conjuntos residenciais brasileiros mostrou que a gama de fatores de conservação é muito diversa. Ela depende da articulação positiva entre vários fatores, que podem ser a efetivação da construção tal como projetada, a sua forma de ocupação, ou, ainda, os vínculos de afetividade estabelecidos pelos moradores, podendo levar a ações mais contundentes. A prevalência de um destes fatores pode influenciar positiva ou negativamente sua conservação ou caracterização arquitetônica. (NASCIMENTO, 2016, Capítulo 8)

Nos interessa entretanto, neste momento, discutir mais do que a preservação física como um fim em si mesmo, mas pensar os vínculos de memória e de pertencimento que os moradores construíram com os espaços de moradia. Os conjuntos habitacionais foram erguidos pelo Estado como parte das políticas para os trabaIhadores. Desde as pesquisas de ngela Castro Gomes feitas nos anos 1980, que se sabe o papel central dos trabalhadores na construção do estado autoritário do Governo Vargas e, do mesmo modo, compreende-se de modo dicotômico o lugar da sociedade na conformação dos estados autoritários. (ROLLEMBERG \& QUADRAT,
2010) Pergunta-se, portanto, quais seriam padrões de domesticidade do trabalhador moderno, nacional, sindicalizado e pronto para atender às demandas por ordem social permeadas pela lógica do trabalho foram respondidas na esfera privada? Estes são temas que instigam a compreensão, no presente, do papel dos moradores no protagonismo da construção de suas histórias e, portanto, que visam potencialmente pensar na sua preservação.

As pesquisas tem mostrado o papel primordial dos moradores na apropriação das casas modernas e na assimilação, rejeição ou resistência aos modos de vida propostos seja nas esferas domésticas, seja nas atividades sociais, culturais e desportivas nos conjuntos. (NASCIMENTO, 2016) A experiência de moradia coletiva realizada a partir dos programas estatais levou a formas de organização social e produziu experiências muito fortes e duradouras, constantemente contadas e reinterpretadas pelos moradores. A utilização dos espaços de morar no presente é revestida de significados memoriais, repleta de histórias pregnantes da apropriação pelos moradores de suas casas modernas e dos espaços de viver coletivamente, os quais denotam a força dos programas promovidos pelo Estado naquele período e o campo muito fértil de investigação sobre a história social da habitação ainda inexplorado.

O estudo teve por objetivo compreender as relações entre o papel dos agentes sociais e o espaço 


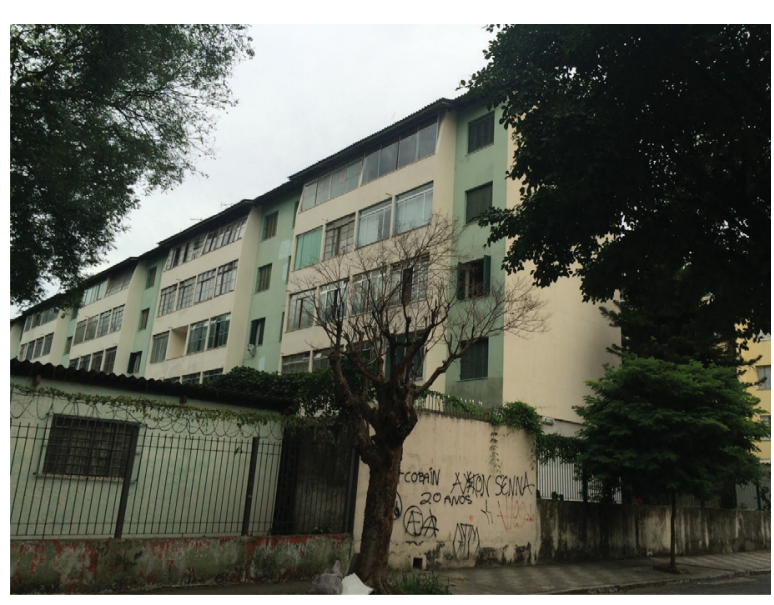

Figura 1. Conjunto Residencial Mooca, 2016. Fonte: Acervo da Autora.

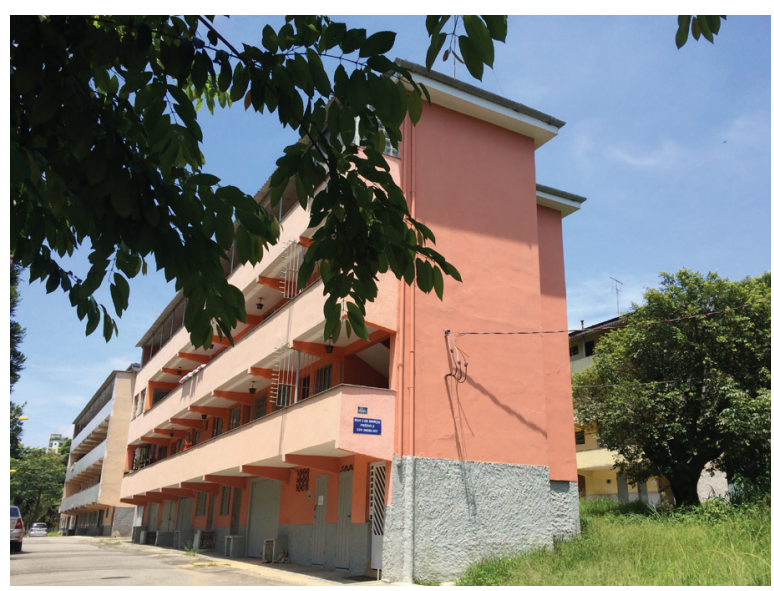

Figura 2. Conjunto Residencial Vila Guiomar, 2016. Fonte: Acervo da Autora. edificado a partir da apropriação, resistência ou rejeição ao modo de morar moderno. O processo de pesquisa constituiu-se de visitas de campo aos conjuntos selecionados e entrevista orais. As entrevistas foram realizadas com moradores que pudessem, de alguma forma, estabelecer relações de memória dos seus modos de vida à época da implantação do projeto de morar, nos anos 1950. Quase todos os entrevistados pertencem à geração das primeiras famílias beneficiadas com uma unidade pelos Institutos de Aposentadoria e Pensões em seus respectivos conjuntos.

Para tanto, foi elaborado um questionário com perguntas semiestruturadas, que continham alguns pontos cruciais para estabelecer diretrizes e relações entre as memórias relatadas e os dados historiográficos. Nas entrevistas foram abordadas questões como as datas de aquisição e mudança para a unidade a qual a família fora beneficiada, os trâmites no processo de aquisição dessa unidade, as exigências propostas pelos Institutos de Aposentadoria e as formas pelas quais ocorria a divulgação dos processos seletivos. Foram realizadas, também, perguntas de cunho socioeconômico, referentes ao número de integrantes da família, a distribuição desses entre os cômodos da unidade, informações sobre o mobiliário da época e sua disposição. Tais questões tinham o objetivo de compreender o contexto no qual estava inserido o cotidiano dessas famílias, o funcionamento e dinâmica doméstica nesses núcleos através do papel desempenhado por cada um de seus indivíduos. As entrevistas foram, na maioria dos casos, realizadas nos apartamentos dos moradores nos conjuntos residenciais.

\section{Os conjuntos residenciais na cidade: trajetórias urbanas e sociais}

Do universo de conjuntos habitacionais construídos pelo Estado no Brasil entre 1940 e 1950 foram selecionados cinco localizados na cidade de São Paulo e em Santo André, região metropolitana, aos quais foi possível ter acesso aos moradores. Três conjuntos eram do Instituto de Aposentadoria dos Industriários (IAPI) - Vila Guiomar em Santo André, Mooca, no bairro operário de mesmo nome, e Várzea do Carmo, na baixada do Glicério - e outros dois dos Bancários - Nove de Julho no Itaim Bibi e Santa Cruz, na Vila Mariana. Os conjuntos dos industriários destinavam-se a trabalhadores empregados em ofícios ligados à indústria. Embora fossem uma elite dos trabaInadores da indústria, se comparados aos bancários, tinham um perfil mais escolarizado e de renda maior. Ainda que todos fizessem parte do projeto mais amplo de fornecimento de habitação aos trabalhadores pelo estado varguista, no que se refere ao perfil da população residente e à arquitetura há diferenças importantes de serem apontadas, e também, no que se refere à constituição dos programas habitacionais.

Os três conjuntos residenciais promovidos pelo IAPI - Mooca (Figura 1), Vila Guiomar (Figura 2) 


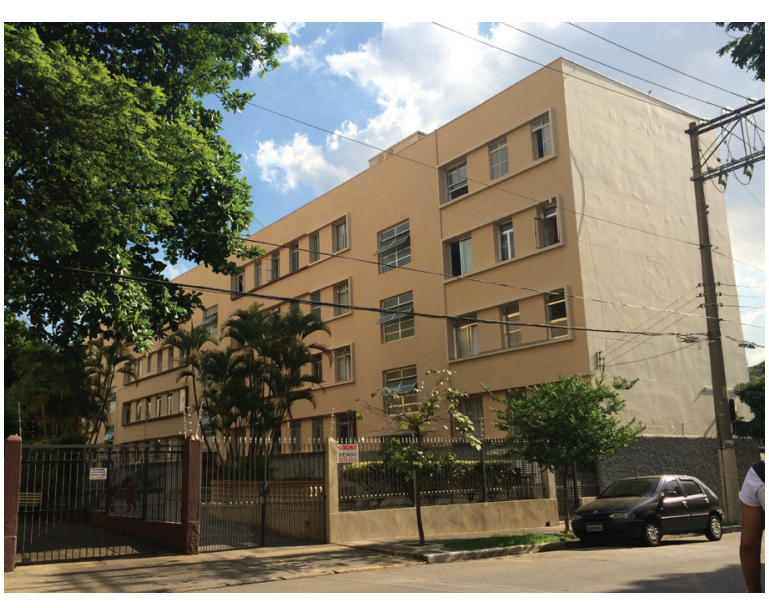

Figura 3. Conjunto Residencial Várzea do Carmo, 2015. Fonte: Acervo da Autora. e Várzea do Carmo (Figura 3) - fazem parte do primeiro momento de atuação do instituto e representam, na sua materialidade, as reflexões e realizações habitacionais a seu tempo. O Instituto foi fundado em 1936 e tornou-se o maior órgão de seguridade social do país, funcionando até 1966, quando foi integrado ao Instituto Nacional de Previdência Social (INPS). Assim como os demais Institutos de Aposentadorias e Pensões, tinha como objetivo fornecer seguridade social aos associados, sendo a promoção de habitação social uma forma de investimento de recursos. Tornou-se um órgão importante no que se refere à modernização da administração pública, sendo um dos primeiros a fazer concursos públicos. $O$ IAPI foi o principal promotor de habitação social no Brasil. Para tanto, constituiu um Setor de Engenharia com diversos arquitetos e engenheiros em seu corpo técnico, muitos destes admitidos por concurso público. O principal idealizador do programa habitacional do IAPI em seu momento de constituição foi arquiteto carioca Carlos Frederico Ferreira. Formado pela Escola Nacional de Belas Artes - ENBA - ligou-se ao pensamento da arquitetura moderna formulado pelos Congressos Internacionais de Arquitetura Moderna (CIAM) e tratou, nos primeiros anos de estruturação do programa habitacional do IAPI, de aplicar os conceitos de racionalização da construção, seriação e estandardização. O Conjunto de Realengo, de 1938, no Rio de Janeiro, de autoria de Carlos Frederico, foi o primeiro planejado e edificado pelo IAPI. Ele congrega as diversas hipóteses e expe- riências do morar neste período, com blocos de apartamentos e casas isoladas, além de técnicas diversas de racionalização da construção. Após a experiência inaugural, partiu-se para a sistematização de novas experiências, cuja principal marca foi a contratação de profissionais externos, de fora do corpo burocrático do órgão, mas, naturalmente, seguindo as suas orientações técnicas. (BONDUKI \& KOURY, 2014, p. 15-101; ARAVECCHIA-BOTAS, 2016)

Os conjuntos de São Paulo em que realizamos o projeto de história oral foram concebidos e construídos na fase inicial do órgão, ainda sem corpo técnico completo e experimentando as possibilidades e modelos de morar, e também recorrendo em alguns casos a arquitetos com práticas privadas para realizar os projetos. O primeiro deles é o Conjunto Residencial da Várzea do Carmo, projetado por Attílio Correa Lima e equipe, construído apenas parcialmente. Elaborado em 1938, é composto por blocos laminares de quatro pavimentos, com unidades de três dormitórios. A ele se seguiram o Edifício Anchieta (1941) dos Irmãos Roberto e o Japurá (1942) de Eduardo Kneese de Mello. (ARAVECCHIA-BOTAS, 2016)

O Vila Guiomar (1942) em Santo André/SP, de Carlos Frederico Ferreira, é um dos maiores conjuntos estudados, com 1.411 unidades residenciais, formado por blocos laminares numa grande gleba e casas unifamiliares. O Conjunto da Mooca é o último deles, elaborado em 1946 pelo também 


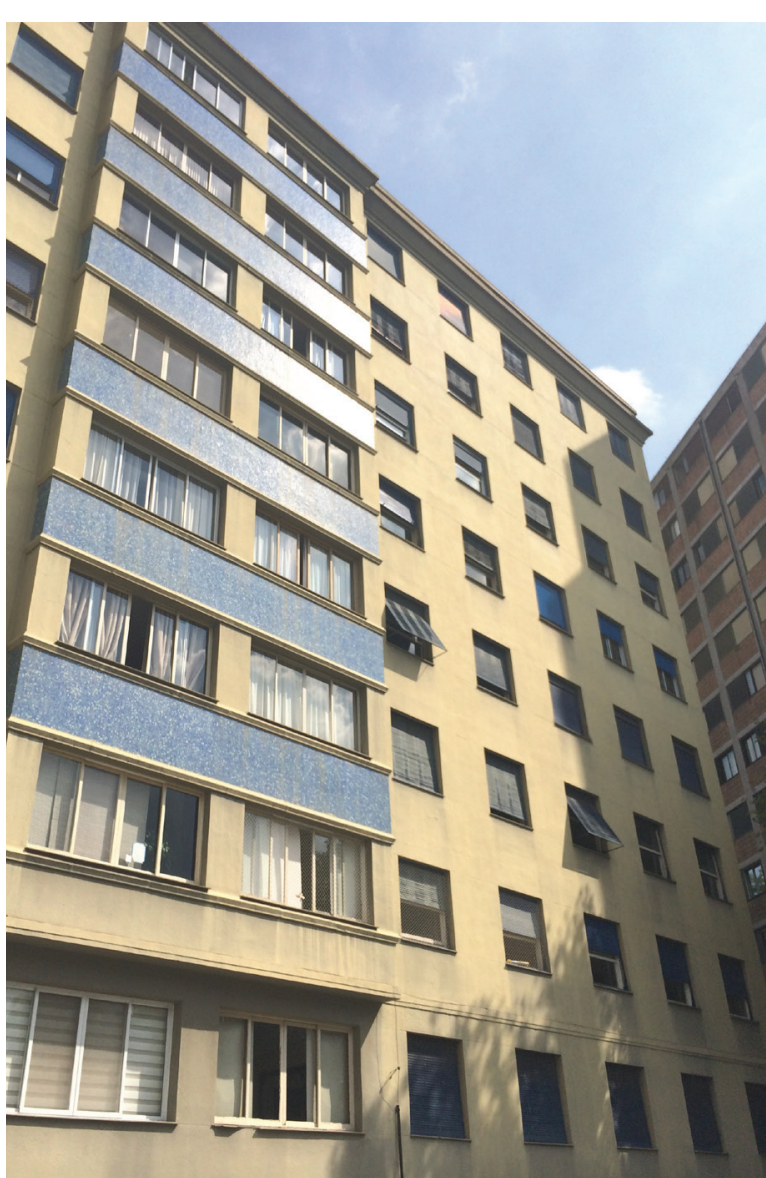

Figura 4. Conjunto Residencial Nove de Julho, 2016. Fonte: Acervo da Autora. carioca Paulo Antunes Ribeiro (que realizou outros projetos para o IAPI), constituído por blocos laminares soltos no lote em meio a grandes áreas verdes. Todos os conjuntos incluídos no escopo do trabalho de pesquisa localizavam-se à época em regiões industriais da metrópole paulistana.

O Instituto de Aposentadoria dos Bancários tinha concepção diferente do IAPI, o que se refletiu no seu programa habitacional. Voltado para os bancários, que nos anos 1940 e 1950 eram uma categoria profissional prestigiosa, caracterizou-se por realizar edifícios em áreas urbanas mais centrais, geralmente com torres únicas em lotes urbanos menores, comumente reconhecidos como "edifícios dos bancários". Os conjuntos paulistanos aqui estudados diferem desta lógica, compostos por blocos que se repetem de maneira seriada com muitas unidades habitacionais, como é o caso do Santa Cruz, do engenheiro Marcial Fleury de Oliveira. O Conjunto Residencial Nove de Julho (Figura 4), de 1945, é de autoria do corpo técnico do Instituto e tem três torres altas de apartamentos. Ambos conjuntos estavam, à época de construção, situados em áreas de expansão urbana da cidade. (BONDUKI \& KOURY, 2014, p. 179-233)

Em todos os casos estudados, à exceção do Conjunto Residencial Várzea do Carmo, a situação urbana do entorno das moradias mudou muito desde a época da construção, quadro que se intensificou nos anos mais recentes. Os conjuntos estão em locais que vem sofrendo intensos processos de valorização fundiária, com condomínios e comércio de alto padrão modificando a vizinhança e os modos de ocupação na cidade. O conjunto Várzea do Carmo é o único destes que não teve a sua configuração urbana alvo de grande especulação ou valorização imobiliária. Localizado na Várzea do Tamanduateí, no início da Zona Leste de São Paulo, está inserido numa área de grande circulação urbana. Muito próximo ao centro, mas na passagem da colina histórica com início da zona leste, na várzea do Rio Tamanduateí, é circundado por vias expressas e equipamentos públicos, como as instalações do posto do INSS. Ainda que edifícios novos com padrão construtivo alto tenham surgido no entorno, eles são em número pouco expressivo e em apenas uma das áreas do conjunto, que tem grandes dimensões. A região não se configurou como um bairro residencial, embora os moradores tenham uma forte identificação com o local, mencionando-a, inclusive como um valor afetivo e imobiliário do conjunto.

Na Mooca, a desindustrialização levou ao fechamento de várias fábricas onde, inclusive, trabaIhavam os familiares dos moradores do conjunto residencial. As fábricas têm sido vendidas sistematicamente e são demolidas para a construção de condomínios fechados de alto padrão. $O$ bairro de identidade operária, que se vê na foto de divulgação do conjunto com a chaminé ao fundo, é agora circundado por edifícios de grande altura, chamado de "alto padrão imobiliário" organizados 


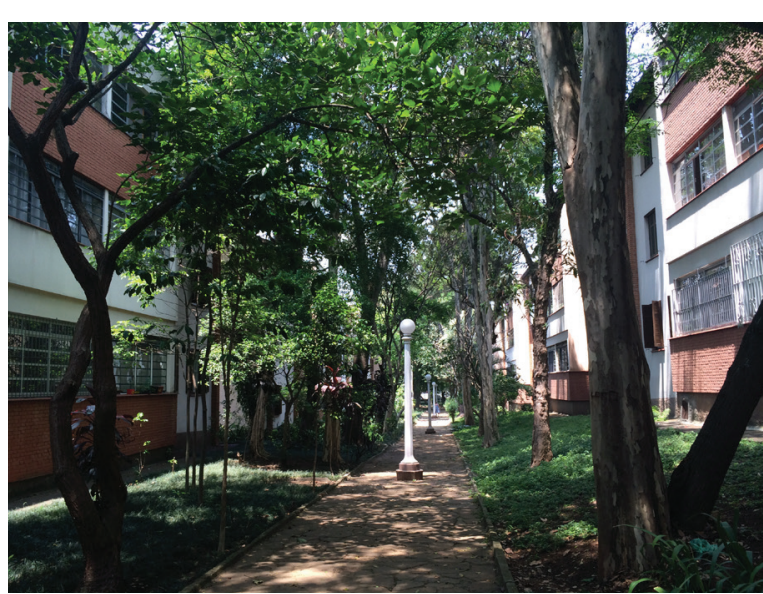

Figura 5. Conjunto Residencial Santa Cruz, 2015. Fonte: Acervo da Autora.

2. Adotaram-se aqui identificações neutras de modo a preservar a identidade dos entrevistados. como condomínios fechados. A paisagem urbana do bairro transformou-se substantivamente, o que também vem gerando mudanças paulatinas no perfil dos moradores do conjunto habitacional. (RUFINONI, 2013)

Situação similar sofreu o conjunto Nove de JuIho, formado por três blocos altos, unidos por um jardim comum. A abertura da Avenida Nove de Julho como via estruturante da circulação paulistana, seccionou o conjunto, trazendo para a região grande vetor imobiliário na cidade. $\mathrm{O}$ bairro do Itaim Bibi, onde se situa, é um dos mais valorizados na cidade, com empreendimentos residenciais de alto padrão e vigorosa área comercial. Relatos dos moradores dão conta de uma região pouco ocupada e valorizada nos anos 1940 e 1950, nas franjas urbanas da cidade, no limite dos bairros jardins.

No Vila Guiomar, no município de Santo André, a configuração urbana de valorização fundiária do entorno das residências se repete, porém, de modo ainda mais agudo. Em razão das dimensões do conjunto, ele forma uma ilha urbana em meio ao entorno que se tornou um bairro de classe média alta na cidade. Muito próximo da área central do município, onde está o Paço Municipal e a estação de trens. (COSTA, 2015; SILVA, 2018) O Conjunto Santa Cruz (Figura 5) localiza-se na Chácara Klabin, às margens do Córrego do Ipiranga, hoje canalizado para dar lugar à Avenida Ricardo Jaffet. À época de sua construção, o rio era aberto e nas suas margens localizavam-se fábricas como a Arno e um incinerador de lixo, ambos desativados há poucos anos. (CANDRO, 2017) As terras da região eram de propriedade da família Klabin, que realizou o loteamento do bairro, construindo na parte alta do terreno algumas de suas casas particulares, como Casa Modernista. A porção mais baixa do terreno, menos valorizada, foi cedida para os usos industriais e o conjunto habitacional. Uma das maiores favelas de São Paulo, a Vergueiro, formou-se nas imediações da várzea do rio, até ser extinta, com a expulsão dos moradores nos anos 1970. O conjunto era relativamente isolado em relação à cidade, sequer transporte público chegava, tendo os bancários que contar com ônibus fretados que levam todos os dias para o centro da cidade onde estavam as agências bancárias.

O comércio era pouco, à exceção de pequenas quitandas e a loja do IAPB, como conta um dos moradores ${ }^{2}$ :

(...) era tudo deserto, tinha nada, o que que tinha em volta? Chácaras. Aqui em volta tinha tudo chácaras. Bom, o que se fazia? De sábado ia meu pai, minha mãe, e eu, as vezes minha irmã ia junto, ia fazer compra no mercado no Ipiranga, porque aqui não tinha nada. é, isso aqui era fazenda, filha, em frente ao hospital santa cruz, você vê a casa modernista, já ouviu falar da casa modernista? (...) ali é a sede da fazenda... da família Klabin, que era dona de todo esse terreno enorme, então ele era assim, seguindo a fazenda, pois bem, e não tinha mais nada por aqui, escola 
não tinha, comércio não tinha, meu pai, como um, os primeiro que vieram aqui, depois que compraram, foram à prefeitura pra fazer uma escolinha aqui dentro, de primário. (Entrevistado VL, 02/10/2015. Conjunto Residencial Santa Cruz)

A extinção da favela e o loteamento do bairro Chácara Klabin, mudou o padrão imobiliário do entorno, trazendo novo perfil de moradores nos anos 1990. A mudança consolidou-se nos anos 2000 com a chegada do metrô da Linha Verde que dá acesso à Avenida Paulista. O impacto imediato do metrô, que fica a menos de 500 metros do conjunto, foi a valorização imobiliária das unidades e a construção de novos empreendimentos imobiliários residenciais. A antes área quase rural da cidade (com fábricas, mas também com chácaras de imigrantes japoneses) está imersa na circulação da metrópole, com metrô e grandes avenidas com acesso imediato. (CANDRO, 2017; IMBRONITO, 2016)

A cidade mudou e mudaram também as moradias, nas suas formas de apropriação, domesticidade e composições familiares. O que antes era uma condição de moradia de "seu tempo", torna-se, agora, uma moradia de "outro tempo" em que as formas de trabalhar e viver a ela associadas mudaram radicalmente. As profissões industriais e bancárias que amalgamavam as experiências de vida nos conjuntos, formando uma identidade industriária ou bancária muito significativa, é hoje parte do passado em que o esta- do de bem estar social compromisso de formação do operariado. (ARAVECCHIA-BOTAS, 2016) Como já indicou Madeleine Ribérioux (1992), a vida de trabalho e seus sentidos cotidianos são tão importantes quanto os espaços de produção industrial. Neste sentido, a expansão para além das fronteiras estritamente arquitetônicas na valoração do que pode ser o patrimônio moderno ou industrial, deve considerar os espaços do morar. (NASCIMENTO \& SCIFONI, 2015)

Os descendentes e moradores dos conjuntos estudados estão ainda muito fortemente acordados em torno da identidade que era de seus pais, mas também lhes é própria. Por meio das memórias, pudemos compreender como a casa é uma importante ancoragem destas experiências subjetivas. A residência e o conjunto, apesar das muitas transformações, é uma materialização da existência pregressa e que lhe confere sentido no presente, articulando, a um só tempo, o patrimônio venal ao patrimônio afetivo e cultural. Aquilo que se recebeu da família como herança, faz parte do conjunto comum das experiências vividas.

\section{Viver o presente: memória, história oral e os conjuntos na temporalidade}

Se a cidade de São Paulo se transformou muito desde o período da construção dos conjuntos até os anos 2000, se as formas de trabalho que amalgamavam os moradores também se extinguiram ou mudaram, muitos daqueles oriundos do pe- 
ríodo inicial e/ou seus descendentes continuam como residentes no conjunto. Uma das perguntas estruturadoras do projeto de história oral foi entender como os moradores elaboram as vivências do passado na contemporaneidade e como ressignificam o lugar histórico de moradia.

Como já mencionado, uma peculiaridade fundamental dos conjuntos brasileiros construídos dos anos 1930 aos 1950 é o perfil da população residente. Ainda que muitas das unidades tenham sido vendidas pelos moradores originais (após a possibilidade de aquisição na década de 1970 em diante), a configuração social tem ainda semelhanças com aquela estabelecida inicialmente, permanecendo os vínculos identitários e memoriais da época de implantação dos programas dos IAPs, seja dos bancários, seja dos industriários. As habitações são ocupadas pelos trabalhadores vinculados ao Instituto que o construiu, e, após os primeiros contatos feitos em campo ou com a ajuda das mídias sociais, abriram-se novos nomes de entrevistados, que foram se ampliando à medida que a pesquisa transcorria.

Ecléa Bosi (1994), em seu clássico estudo sobre as memórias de velhos em São Paulo, mostra como o lembrar é um trabalho que envolve as dinâmicas do presente e as tensões entre o que se quer esquecer e o que, no momento, se quer recordar. Os velhos, como categoria social, exercem o trabalho de lembrar como parte de uma função social no presente. A função da memória, que se localiza no tempo do fim de um transcurso da vida confere sentido à existência. As entrevistas foram realizadas com os moradores que vieram morar nos conjuntos quando crianças ou jovens e hoje têm, em geral, mais de sessenta anos, no momento em que o programa habitacional do Instituto de Aposentadoria e Pensões já está extinto há mais de 50 anos e em que estão aposentados. Lembrar e esquecer neste momento faz parte de construir significados para uma existência em balanço. O momento da vinda ou nascimento no conjunto e passagem do tempo e das experiências de vida são entremeados pela nostalgia da infância perdida, mas, também, pelo orgulho da moradia hoje, com a história que carrega e seus significados históricos para o presente. Esta pareceu ser uma tônica importante de um sentimento geral sobre a moradia. Os moradores atuais tem consciência histórica de seu lugar e vinculam o orgulho da casa a esta história.

O projeto de história oral teve como objetivo trabalhar com uma fonte histórica diferente daquelas já utilizadas para estudar os conjuntos habitacionais. Por meio das lembranças e vivências dos moradores buscou-se ampliar a compreensão histórica destes lugares. O objetivo não era extrair uma suposta verdade da história, o que seria naturalmente impossível, mas conhecer por meio de quem viveu nos locais, as experiências e lembranças de lugares que julgaram importantes. Após os extensivos estudos historiográficos realizados sobre os conjuntos, conhecer mais 
proximamente os sujeitos sociais da história da habitação pareceu ser um passo necessário. Está claro aqui que se admite a subjetividade do ofício do historiador e de suas fontes, sendo os testemunhos diretos, mesmo nas suas contradições e supostas "inveracidades", uma fonte adicional de pesquisa. (FERREIRA, 2002) Estando definidas as fronteiras entre a história e memória, em que a história é uma forma intelectual de conhecimento, uma operação cognitiva, e a memória está no campo das representações sociais (MENESES, 1992), tivemos nos relatos orais ricas possibilidades de compreensão da história social da moradia e dos trabalhadores em São Paulo.

A história oral vem sendo utilizada pelos historiadores desde meados do século XX, com críticas e ressalvas, mas é incontornável como fonte histórica. É largamente utilizada na prática historiográfica nacional, sobretudo diante do crescimento dos temas da memória da sociedade contemporânea. (FERREIRA, 2002) As fontes orais tem contribuído para a escrita da história dos excluídos, ajudando na construção de identidades e de lutas sociais pelo direito à memória, também colaborando com a construção da história pública. Nos estudos de história da arquitetura e do urbanismo, todavia, a história oral permanece como um campo a ser explorado, sobretudo em face de experiências já realizadas em outros países como México, Argentina e França. (GARAY, 2002, 2004; ABOY, 2005; MICHEL, DERAINNE, 2005)
Para a realização da pesquisa utilizamos fontes que pudessem problematizar as dimensões da vida material nos conjuntos residenciais pela ótica dos moradores - trabalhadores oriundos das camadas populares e médias. É na crítica às fontes e no cotejo das visões sobre o operariado e a ingerência estatal pelo Estado e dos próprios trabalhadores sobre suas casas que buscamos compreender as formas de morar nos conjuntos habitacionais. Como mostrou Roger Chartier (1988), "as maneiras como dado grupo se apropria de um motivo intelectual ou de uma forma cultural são mais importantes do que a distribuição estatística desse motivo ou dessa forma." Segundo Meneses (1992) a memória tem a condição de fato social: é produto do presente, para responder as solicitações do tempo histórico vivido. Neste sentido, ela não pode ser resgatada, como se estivesse pronta em algum recôndito, esperando pela hora de subir à superfície.

Os moradores entrevistados são, em sua grande maioria, da primeira geração de ocupantes. Nasceram ou vieram crianças para o conjunto e os pais eram ligados aos ofícios da indústria, em trabalhos diversos, como torneiro mecânico, tecelã, funileiro, encarregado ou fiscal de produção, professor de ensino técnico, até comerciante de livros. Ou no caso dos bancários, trabalhando nas agências bancárias do Centro de São Paulo. Tanto para bancários, quanto para industriários, saíram de uma situação de moradia de aluguel, 
lembrada como precária fisicamente (pequena, banheiro compartilhado, em vilas, etc) ou socialmente (dividida com parentes).

A família do meu pai morava ali no Belém e a da minha mãe também, mais aqui pra Mooca, mas também fazia parte do bairro italiano. Eles casaram e foram morar só um quarto e cozinha por pouco tempo, no Belém também. (Entrevistada CR, 12/03/2016, Conjunto Residencial Mooca)

A mudança para o conjunto significou uma meIhoria material para a família. São citadas as impressões em geral das mães (que passaram a ter mais espaço ou autonomia), pois os entrevistados eram crianças à época. Eles reproduzem, neste ponto, as falas e narrativas familiares sobre a história de seu morar. Mesmo sendo pequenos, os apartamentos, com um, dois ou três dormitórios, para famílias com três a quatro filhos, este não é citado como um problema, face às condições anteriores do morar. As condições materiais da casa são apreciadas como um ganho material:

Minha mãe quando morava na São Joaquim, eles moravam naquelas casinhas que era quarto e cozinha! Não importa que o lugar era longe, feio.. era meu. Aquele sonho da casa própria. Quando chegou aqui ela fala assim: "a primeira coisa que eu vi era que ventava". O dela é de esquina. Daí podia secar as fraldas, que eram pano. (Entrevistada PC, 29/02/2016, Conjunto Residencial Várzea do Carmo)
O aluguel nas casas anteriores à mudança para o conjunto era também um fator mencionado de precarização da moradia anterior à ida ao conjunto. No entanto, é citado que nos IAPs a moradia não era gratuita, pagava-se um valor monetário, que não era baixo. Este valor de aluguel é lembrando como sendo uma prestação da compra. Mas, os imóveis construídos pelo Estado para os trabalhadores eram alugados, ficando de propriedade do IAP que administrava os condôminos, desde a seleção até a organização da vida em comunidade, em alguns casos com o auxílio de assistentes sociais. Principalmente nos conjuntos residenciais do Instituto de Aposentadorias e Pensões dos Industriários, o IAPI, houve a atuação direta e ativa das assistentes sociais nas mais diversas dimensões da vida, no âmbito privado ou público.

As habitações construídas durante ○ Estado Novo transcendiam os sentidos do mero teto que abriga; com elas se pretendia a conformação e educação do trabalhador. Em alguns casos, a administração das unidades não era apenas burocrática, mas advinha de tais convicções e foi, muitas vezes, proximamente acompanhada de trabalhos sociais, nos quais as assistentes sociais tiveram papel ativo. Em maior ou menor grau, dependendo da localidade e época de inauguração, a administração pelos IAPs foi presente. (NASCIMENTO, 2008) Nos conjuntos paulistas não há lembranças da atuação social dos Institutos. Eles são mencionados por meio do 
escritório para o pagamento do aluguel da casa, que no IAPI da Mooca ficava em um dos apartamentos do conjunto. O IAPI fornecia a segurança (com dois guardas que faziam a ronda noturna do conjunto) e a limpeza dos edifícios. De resto, não há relatos de intervenção no morar por parte do Instituto.

Nos anos 1960, teve fim a administração direta dos conjuntos pelos Institutos que eram essenciais ao projeto mais amplo de ideologia do trabalhador brasileiro. Com o fim dos IAPs e a instalação do $\mathrm{BNH}$, as moradias foram postas à venda. A venda das unidades residenciais significou a dissolução definitiva do projeto social, levando à gestão pelos moradores. Os moradores tiveram que se organizar em condomínios, cuja forma de criação determinou a divisão ou a unidade dos blocos, decorrente da própria capacidade associativa dos residentes.

Os moradores entrevistados relatam que o processo de compra foi quase uma passagem natural: o valor das prestações de aluguel valeu para eles como um valor depositado para compra. Apagou-se, com o tempo, o próprio projeto do morar do Estado, o qual, talvez não estivesse tão claro para os moradores nestes conjuntos estudados, sobretudo em tratando de serem principalmente filhos daqueles que assinavam os contratos de locação. Passados tantos anos da ocupação e da dissolução do programa de moradia estatal, restam os objetos materiais e suas lembranças.
O fato de as casas existirem como propriedade familiar é fundamental. As transformações físicas que para os arquitetos e estudiosos podem ser desconcertantes, são para os moradores, mais naturalizadas, sentidas como necessárias. Para os moradores, nos chamou a atenção o fato de lidarem com as mudanças como sendo necessárias à época, tais como o gradeamento dos edifícios da Mooca ou de todo o conjunto de Santa Cruz. O fechamento em condomínios garante a segurança e é visto como inescapável, frente às mudanças que foram chegando, muitas vezes sem aviso. (Entrevistado FC, 07/11/2015, Conjunto Residencial Santa Cruz) As mudanças físicas para os moradores parecem ser menos significativas frente àquilo que efetivamente se perdeu, como o trabalho assalariado, a vida em comunidade e familiar. Menos do que a memória de um projeto ou do momento de construção os moradores tem a própria experiência de vida e da temporalidade vivida como parâmetros de afeto e valoração.

A vida comunal é mencionada sempre como algo muito positivo. O perfil dos moradores era relativamente homogêneo, com famílias jovens, em formação, com pai, mãe e filhos (em maior ou menor número). Escapavam deste perfil poucas famílias, em geral de viúvas, pois os Institutos exigiam atestados de formação familiar. O responsável pelo contrato de locação deveria ser casado, sendo que os casais sem filhos recebiam os apartamentos de um quarto (no caso do Moo- 
ca) e as famílias maiores com dois dormitórios ou mesmo os duplex. A variação tipológica dos conjuntos e das casas era feita prevendo-se o crescimento familiar e/ou os tamanhos distintos. Hoje, a diferença de tamanho serve também como o mesmo fim, porém, nos apartamentos pequenos do Mooca, localizados no andar térreo, residem muitas pessoas idosas, sobretudo viúvas.

Mesmo sem o projeto do Estado de gerenciamento do morar, houve um associativismo que deu a tônica da forma de viver nos conjuntos e que amalgamam os vínculos afetivos e memoriais dos moradores com seus espaços. Este é um elo fundamental que liga as pessoas ao passado nos conjuntos. As associações de moradores promoviam diversas atividades, como bailes, carnavais, exibição de filmes, festas juninas e campeonatos de futebol. Os momentos de sociabilidade são os mais citados como parte de um passado que não retorna. Nos conjuntos da Mooca, Santa Cruz e Vila Guiomar os moradores formaram associações que tinham como por objetivo as atividades sociais, que eram feitas no local. Elas eram ações independentes dos moradores, sem a mediação dos Institutos. (Entrevistada CR, 17/10/2015, Conjunto Residencial Santa Cruz; Entrevistado FS, 07/11/2015, Conjunto Residencial Santa Cruz $O$ que se lembra primeiramente quando se remete à infância vivida nos conjuntos é o espaço de liberdade. Todos os conjuntos estudados, exceto o Nove de Julho que é conformado por torres altas, tem a tipologia de blocos residenciais de até cinco pavimentos, soltos numa grande gleba. Implantados em paralelo, sem cercas ou gradeamentos, os blocos deixavam ao seu redor grandes áreas livres de edificação que eram ocupadas com jardins e parquinhos infantis. A ausência de carros e de estacionamentos e até mesmo de árvores, que eram poucas nos conjuntos recém-construídos, deixavam grandes áreas livres que eram território das crianças. Nas memórias, os conjuntos formam uma paisagem infantil, repleta de crianças de todas as idades que passavam o dia pelo conjunto e seu entorno, os bairros operários de São Paulo.

(...) era tudo aberto, tinha um jardim enorme no meio e atrás tinha um playground pras crianças. Todos tinham, a própria construtora fez tudo com balancinho e escorregador. A maioria dos moradores tinha cinco ou seis filhos! (...) Porque a criançada foi fazendo, não ficava no apartamento, descia e ficava naquela área enorme brincando: bicicleta, bola, era uma loucura! (Entrevistada PC, 29/02/2016, Conjunto Residencial Várzea do Carmo)

Nossa, ia pra rua. Eu acho que os pais abriam as portas da rua e fala: "Vai!" era assim mesmo, assim que eram os pais. (Entrevistada CR, 17/10/2015, Conjunto Residencial Santa Cruz)

No IAPB de Santa Cruz, a referência é feita também aos serviços fornecidos como um mercado onde se compravam produtos básicos a preços mais baratos e à assistência médica e dentária. A escola primária é, assim como no IAPB Nove de Julho, uma lembrança importante. Embora 
da prefeitura, em ambos os casos, a escola era parte integrante do programa do morar. Em Santa Cruz a escola é um edifício separado que era vastamente utilizado pela comunidade em outras atividades sociais promovidas. Neste conjunto, os bancários manejaram a criação de um condomínio para todos os blocos, assegurando sua unidade. Com isso, não houve o gradeamento isolado e individual de cada bloco, mas sim do conjunto inteiro. Outros conjuntos não tiveram tal fortuna, e os condomínios foram criados bloco a bloco, implicando no cercamento individual e na progressiva privatização dos espaços semi-públicos, como jardins e praças, como é o caso do Mooca. (FRASSON, 2000, p. 182-191)

A cidade de São Paulo nas imediações dos conjuntos foi uma grande personagem nas entrevistas. As quadras próximas aos conjuntos e, em alguns casos, até o mesmo o bairro, eram vividas intensamente pelos moradores e são lembradas em detalhes. São reminiscências de uma cidade com aspectos rurais, com os rios ainda não canalizados nos quais se brincava e se convivia com as enchentes, com chácaras onde se compravam alimentos, passeava, brincava, jogava futebol, ou se fazia tarefas cotidianas como secagem de roupas. (Entrevistado FS, 07/11/2015, Conjunto Residencial Santa Cruz; Entrevistada MR, 30/09/2015, Conjunto Residencial Mooca)

Aqui, mesmo em São Paulo, onde eu estou, era tido como um lugar de periferia, a Mooca, e tinha um rio, tem um rio aqui nessa Rua Caçandoca, tem um rio canalizado. Quando eu era criança, o rio era aberto, era tudo barro ali. Nós quando éramos moleques nadávamos no rio, a molecada nadava no rio. (Entrevistado RJ, 03/10/2015, Conjunto Residencial Mooca)

Tais referências constroem uma cidade vivida no cotidiano, situada nas franjas da centralidade financeira e industrial, mas profundamente ligada à ela. Na qualidade de trabalhadores dos bancos e das indústrias, os moradores viviam a cidade do trabalho, mas seus filhos e eles próprios habitavam, geograficamente, nos limites desta centralidade. Como já mencionado, os conjuntos, em todos os casos, foram pioneiros na ocupação das porções de cidade em que se implantavam. Construía-se a moradia para o trabalhador, mas era implantada em locais de pouco valor, o que se atesta pelas narrativas das histórias de vida.

A chave de entendimento da cidade habitada nos limites da urbanização não era segregadora, mas de acolhimento e proporcionadora de ricas experiências, como o contato com a natureza e a vida em liberdade. As memórias traumáticas, ou mesmo de crítica à vida em conjunto raramente vieram à tona nas entrevistas. A articulação de lembranças é feita em torno do passado feliz, o que não necessariamente se associa ao presente negativo ou ruim. O morar serve como âncora das memórias, que são sempre reinterpretadas. Aos conflitos do passado se dão novas significações. Diante de traumas, elaboram-se esquecimentos e apagamentos. (POLLAK, 1989) As dissenções, 
incoerências e mesmo infelicidades apareceram quando as entrevistas são postas lado a lado. Até mesmo as enchentes que assolavam violentamente o Conjunto Várzea do Carmo, são positivadas. (Entrevistada PC, 29/02/2016, Conjunto Residencial Várzea do Carmo)

Os descontentamentos ou deslocamentos aparecem mobilizados nas lembranças do papel da mãe, esposa ou filha. Mas elas quase nunca são protagonistas das existências familiares e das lembranças. O trabalho do pai, a cidade de São Paulo, os amigos, as festas, o futebol, as brincadeiras, os espaços livres, a casa, são recorrentes. Mas quando perguntados sobre o lazer das muIheres ou suas atividades fora do mundo do trabalho, há sempre hesitações, e a afirmação que os cuidados com tantos filhos e com a casa deixava pouco tempo para outras coisas, que não a costura ou o rádio. (Entrevistado RJ, 03/10/2015, Conjunto Residencial Mooca)

O processo mais intenso de transformação dos conjuntos residenciais coincide com o fim dos institutos e a venda das unidades residenciais, que é também o momento de grande mudança na vida urbana no país e de São Paulo. A urbanização acelerada da capital paulista, com o crescimento das periferias e a metropolização, coloca os conjuntos em outra situação urbana, ficando mais inseridos na cidade formal e próximos à centralidade. Os rios dos entornos são canalizados, grandes avenidas vão sendo abertas, o transporte público chega mais próximo. Tais mudanças são encaradas de modo natural pelos moradores, como parte das mudanças da vida. O gradeamento para proteger as casas, o fim dos jardins para dar lugar aos carros, são vistos como necessidades impostas pela vida. Nos parece que o envelhecimento ou transformação dos conjuntos ocorreu com o envelhecimento das próprias pessoas. (Entrevistado RJ, 03/10/2015, Conjunto Residencial Mooca)

O momento das entrevistas (2015 e 2016) foi, em alguns casos, o de retorno à vida no conjunto, em que os moradores na velhice ou meia idade mobilizam as histórias de vida e de pertencimento à história do habitar operário. As entrevistas realizadas mostraram a pregnância dos projetos de morar instituídos pelo Estado nos anos 1940 e 1950 e, sobretudo, a aderência identitária destes modelos junto aos seus habitantes. Ulpiano Meneses (2017) assinalou a importância.

A caminho de uma conclusão, interessa ainda dizer que, alguns dos casos, transformações ou ameaças foram catalizadoras dos pertencimentos e da luta por preservação dos conjuntos. No Conjunto Residencial da Mooca, a venda da área do parque para um empreendedor privado ameaçou a unidade potencial do conjunto. $O$ fim da muito apreciada área livre e a possibilidade de construção de uma torre alta nos moldes dos edifícios do entorno, chocou os moradores. Quando perguntada se já tinha pensado que o 
conjunto era um patrimônio cultural, uma moradora respondeu: "Olha, nós fomos obrigados a pensar!" O conjuntos emergiram nas lembranças dos moradores e na luta pela preservação na qualidade de referências culturais de uma história de vida de trabalho, sociabilidade e vida cotidiana. Desfocados do objeto em si por seus valores arquitetônicos, os moradores apresentaram suas memórias e sensibilidades capazes de patrimonializar os espaços como parte das vidas de trabalho, sociabilidade e cotidiano. A história oral pode mostrar o quão significativas foram suas experiências e como elas mobilizam os afetos e as emoções patrimoniais. Repovoar o patrimônio mostrou-se mesmo necessário.

As tensas valorações do Conjunto Residencial da Mooca são um bom exemplo das complexidades da expansão da agenda patrimonial, malgrado o aumento de seu conhecimento pela história da arquitetura e do urbanismo. Diante da venda da área livre usada como parque pelas moradoras e da perspectiva de construção de edifícios no seu lugar, as moradoras solicitaram o seu tombamento em nível municipal, que foi acolhido, mostrando a efetiva sensibilização do órgão de patrimônio para com a demanda social. O estudo de preservação indica as valorações dos moradores e justifica o tombamento "considerando os vínculos identitários e afetivos que os moradores do Conjunto Residencial da Mooca mantêm com o local em que residem, entendido como lugar de memória de trabalhadores nas indústrias da região". Os estudos técnicos, fundamentados na produção historiográfica recente, foram favoráveis à preservação, contudo, ao final do processo somente os edifícios foram preservados, e uma altura limite para novas edificações foi determinada, de modo que a área livre vendida tenha uma futura ocupação limitada, mas não impedida em face de um valor patrimonial. Permaneceram os entendimentos mais arquitetônicos que urbanos na valoração do bem cultural. (Resolução 18/ Conpresp 2018)

Seria fundamental pensar os conjuntos habitacionais a partir das ampliações bibliográficas, mas também a partir das apropriações dos moradores, os valores, tensões e críticas às experiências do habitar. Se na historiografia da arquitetura internacional a morte da própria arquitetura foi narrada com as demolições e degradações de conjuntos residenciais, na América Latina as questões parecem tomar outro caminho. Construídos para certos tipos de trabalhadores, os conjuntos estão hoje incorporados à trama urbana das cidades, mas pouco apropriados como parte da história social do trabalho e do trabalhador. A habitação segue como uma das temáticas fundamentais de nossas cidades, que lidam com diversas formas de moradia precária. Mesmo no contexto latinoamericano em que inúmeras obras de habitação social moderna foram construídas, os movimentos de perpetuação deste legado às gerações futuras foram ainda tímidos. 
O entendimento da existência de projeto mais amplo no qual se inserem os conjuntos cria laços afetivos importantes para a preservação. Passados tantos anos da ocupação e da dissolução do programa de moradia estatal, restam os objetos os materiais e as lembranças que Ihe são articuladas. Coletar relatos sobre a vida nos conjuntos, com os aportes metodológicos da história oral problematizou e dimensionou o impacto dos projetos modernos na vida dos trabalhadores e o significado dos modelos de vivenda na vida cotidiana e dos processos históricos vividos pelos moradores nos conjuntos habitacionais.

\section{Referências bibliográficas}

ABOY, Rosa. Viviedas para el pueblo: espacio urbano y sociabilidad en el barrio Los Perales. 1946-1955. Buenos Aires: Universidad de San Andrés/ Fondo de Cultura Econômica, 2005.

ARAVECCHIA-BOTAS, Nilce. Estado, arquitetura e desenvolvimento. A ação habitacional do lapi. São Paulo: Editora Unifesp, 2016.

BONDUKI, Nabil; KOURY, Ana Paula. Os pioneiros da Habitação Social: Inventário da produção pública no Brasil entre 1930 e 1964. Vol 2. São Paulo: Editora Unesp: Editora SESC, 2014.

BOSI, Eclea. Memória e sociedade. Lembranças de velhos. São Paulo: Cia das Letras, 1994.
BRUNA, Paulo. Os Primeiros Arquitetos Modernos. Habitação Social no Brasil 1930-1950. São Paulo: Editora da Universidade de São Paulo, 2010.

CANDRO, Larissa. Permanências. Memória e projeto no Ipiranga. Trabalho final de graduação em Arquitetura e Urbanismo - FAU USP. São Paulo: 2017.

CHARTIER, Roger. A história cultural. Entre práticas e representações. Rio de Janeiro: Bertrand Brasil; Lisboa: Difel, 1990.

COSTA, Ana Beatriz Pahor P. Conjunto Habitacional Vila Guiomar, Santo André/SP: estudo sobre a habitação social e as formas de morar nos anos 1950. Relatório Final de Iniciação Científica. Faculdade de Arquitetura e Urbanismo da USP. Programa de Bolsas da Pró-reitoria de Pesquisa da USP. Orientação Flávia Brito do Nascimento. São Paulo: mimeo, 2015.

FERREIRA, Marieta de Morais. História, tempo presente e história oral. Topoi, Rio de Janeiro, dezembro 2002, p. 314-332.

FRASSON, Alexandra. Habitação social e arquitetura moderna: a apropriação dos conjuntos residenciais dos IAPs (1940-2000). Dissertação (Mestrado) IAU São Carlos, 2000. 
GARAY, Graciela de (Coord.) Modernidad habitada: Multifamiliar Miguel Alemán, Ciudad de México, 1949-1999. México: Instituto Mora, 2004.

GOMES, Ângela de Castro. A invenção do trabalhismo. São Paulo: luperj/Vértice, 1988.

HARRISON, Rodney. Heritage. Critical Approaches. NY: Routledge, 2013.

IMBRONITO, Maria Isabel. "Conjunto residencial Santa Cruz. Da origem até os dias atuais". Pós. Revista do Programa de Pós-Graduação em Arquitetura e Urbanismo da FAUUSP, 23(39), 2016, 54-71.

KOURY, ANA PAULA. Modern housing estates and the production of the Brazilian city (19371960). Planning Perspectives, v. 34, p. 1-31, 2019.

MICHEL, Geniviève; DERAINNE, Pierre-Jacques. Aux Courtillières. Histoires singulières et examplaires. Paris: Creaphis, 2005.

MENESES, Ulpiano Bezerra de. A História, cativa da memória? Para um mapeamento da memória no campo das Ciências Sociais. Revista Instituto de Estudos Brasileiros, n. 34, p. 9-24, 1992.

NASCIMENTO, Flávia Brito do. Blocos de memórias: habitação social, arquitetura moderna e patrimônio cultural. São Paulo: Edusp/Fapesp, 2016.
Memória dos conjuntos residenciais modernos em São Paulo: preservação do patrimônio cultural e educação patrimonial. Relatório de Pesquisa. São Paulo: Faculdade de Arquitetura e Urbanismo da Universidade de São Paulo FAU USP, agosto 2016.

\& SCIFONI, Simone. Lugares de memória: trabalho, cotidiano e moradia. Revista Memória em Rede, v. 7, p. 069, 2015.

O campo do patrimônio cultural: uma revisão de premissas. I Fórum Nacional do Patrimônio Cultural. Vol. 1. Brasília: Iphan, 2009.

Repovoar o patrimônio ambiental urbano. Revista do Patrimônio Histórico e Artístico Nacional, v. 36, p. 39-52, 2017.

Rumores y retratos de un lugar de la modernidad: historia oral del Multifamiliar Miguel Alemán 1949-1999. México: Instituto Mora; UNAM/Facultad de Arquitectura, 2002.

POLLAK, Michel. Memória, esquecimento, silêncio. Estudos Históricos, Rio de Janeiro, vol. 2, n. 3, 1989, p. 3-15.

RIBÉRIOUX, Madeleine. "Lugares da memória operária". In: SÃO PAULO (cidade). Secretaria Municipal de Cultura. Departamento do Patrimônio Histórico. $\mathbf{O}$ direito à memória: patrimônio histórico e cidadania / DPH. São Paulo: DPH, 1992. 
ROLLEMBERG, Denise e QUADRAT, Samantha Viz (orgs.) "Apresentação. Memória, história e autoritarismos". In: Sociedades e regimes autoritários. Europa. Rio de Janeiro: Civilização Brasileira, 2010.

RUFINONI, Manoela. Preservação e restauro urbano. Intervenções em sítios históricos industriais. São Paulo: FAP-Unifesp/ Edusp, 2013.
SILVA, Larissa. Habitação social como bem cultural: valores e conservação do IAPI Vila Guiomar. Trabalho de Conclusão de Curso. (Graduação em Arquitetura e Urbanismo) - Universidade de São Paulo. São Paulo: 2018.

SMITH, Laurajane. Uses of Heritage. Nova York: Routledge, 2006. 